\title{
Cadmium Removal from Aqueous Solution by a Tunisian Smectitic Natural and Activated Clay: Thermodynamic Study
}

\author{
L. Khalfa, M. Bagane \\ Applied Thermodynamics Unit Research, ENIGabes, Zrig Gabes, Tunisia \\ E-mail: \{khalfaleila,drmbag1420\}@yahoo.fr \\ Received October 25, 2011; revised November 22, 2011; accepted December 4, 2011
}

\begin{abstract}
The removal of heavy metals from industrial waste streams has become one of the most important applications in wastewater treatment in terms of protecting public health and environment. The recovery of metals present in the industrial effluents by adsorption onto natural materials constitutes a technological option increasingly studied throughout the world. However, the implementation of such process on an industrial scale requires the use of adsorbents easily available and inexpensive. Clay in these two forms natural and activated answers very well to these two requirements. The present research aimed the study of the capacity of fixing of cadmium present in aqueous solution, by two types of clay: natural and activated. The adsorption capacity of adsorbent was investigated using batch experiments. The influence of $\mathrm{pH}$, temperature and adsorbent dose were investigated and the experimental data obtained were evaluated and fitted using adsorbent equilibrium isotherms. Adsorption isotherms of cadmium onto natural and activated clay were determined and correlated with common isotherm equations such as the Langmuir and Freundlich models. The Langmuir model agrees very well with experimental data. The thermodynamic parameters obtained indicated that the adsorption of cadmium ions onto natural clay was a spontaneous and an endothermic process.
\end{abstract}

Keywords: Adsorption, Isotherms, Cadmium, Naturel Clay, Activated Clay, Modeling

\section{Introduction}

Heavy metals are nowadays among the most important pollutants in surface and ground water. They are extremely toxic elements, which can seriously affect plants and animals and have been involved in causing a large number of afflictions [1]. Therefore, the elimination of these metals from water and wastewaters is important to protect public health. For this reason, development of a new, flexible and environmentally friendly process for treatment of water and industrial effluents is major challenge. The treatments methods, such as chemical precipitation, reverse osmosis, ion exchange and adsorption have been practiced for the removal of heavy metals [2], but these methods are not economical and do not exhibit high treatment efficiency. The adsorption phenomenon has still been found economically appealing for the removal of toxic metals from waste water by choosing some adsorbents under optimum operation conditions.

Cadmium is one of the most toxic contaminants found in the environment and is released into the aqueous system from metal plating, smelting, mining cadmium-nickel batteries, phosphate fertilizers, paint industries, pigments, and alloy industries as well as from sewage [3]. The nervous system appears to be the most sensitive target of Cd(II) toxicity. Adverse health effects due to Cd(II) such as lung insufficiency, bone lesions, and hypertension in humans well documented [4].

Keeping in view the toxic nature of $\mathrm{Cd}(\mathrm{II})$ in water, minimization and removal of this metal from aqueous systems is considered very important. Adsorption at the metal ion mineral interface by clay is often utilized as a very effective way for a scavenging undesirable metal from an aqueous phase.

The present work investigates the feasibility of using clay and their acid-activated forms to removal Cd(II) ions from aqueous solution by adsorption under various conditions.

\section{Materials and Methods}

\subsection{Materials}

In the present work, green clay was selected from site of 
Djebel EL'3idoudi of "Hamma" area, located in south Tunisia was used as raw material.

The as-received material was purified by aqueous dispersion and decantation. After a purification process, the clay remained free of quartz and the fraction with particle size less than $40 \mu \mathrm{m}$ was separated and subjected to activation.

Acid treatments have been used for these samples to increase the surface area of clay minerals and to obtain high porosity.

The activated sample was obtained according to the following procedure: $100 \mathrm{~g}$ of material clay micro-powder, was mixed with an aqueous $\mathrm{H}_{2} \mathrm{SO}_{4}$ solution (acid concentration of $13.8 \%$ ) in a jacketed glass reactor regulated at fixed temperature $\left(75^{\circ} \mathrm{C}\right)$ by a thermostated bath for $3.75 \mathrm{~h}$ under mechanical stirring at $200 \mathrm{rpm}$ [5], and then washed by distilled water for many times until $\mathrm{pH}$ of 6 was achieved. The obtained samples were dried at $60^{\circ} \mathrm{C}$ for $24 \mathrm{~h}$.

\subsection{Experimental Procedure}

Cadmium solutions of different concentrations were made by dilution of $100 \mathrm{mg} \cdot \mathrm{l}^{-1}$ stock solution prepared from analytical grade of $\mathrm{Cd}\left(\mathrm{SO}_{4}\right), 7 \mathrm{H}_{2} \mathrm{O}$.

Adsorption experiments were carried out by batch technique. Batch adsorption experiments were conducted in 200 $\mathrm{ml}$ erlenmeyer flasks by mixing together a constant amount of adsorbent with a constant volume of aqueous solution of cadmium salt.

For all the batch experiments, the solution $\mathrm{pH}$ was adjusted to the desired value by adding $0.1 \mathrm{M}$ of $\mathrm{HNO}_{3}$ or $\mathrm{NaOH}$ and was fixed at $\mathrm{pH}$ 5.5.

The contents in the flasks were agitated by placing them in a water bath thermostat for a know time interval.
Then the suspension was centrifuged and the cadmium concentration ions were determined by atomic absorption spectrometry.

The amount of adsorption was calculated according to:

$$
q_{e}=\frac{\left(C_{0}-C_{e}\right) V}{m}
$$

where $q_{e}$ is the amount of $\mathrm{Cd}^{2+}$ ions adsorbed $\left(\mathrm{mg}^{\cdot} \mathrm{g}^{-1}\right)$, $C_{0}$ is the initial aqueous concentration of $\mathrm{Cd}^{2+}\left(\mathrm{mg}^{-1}\right)$, $C_{e}$ is the equilibrium aqueous concentration of $\mathrm{Cd}^{2+}(\mathrm{mg}$. $\left.1^{-1}\right), V(1)$ is the volume of the solution and $\mathrm{m}$ is the weight of the adsorbent $(\mathrm{g})$.

\section{Results and Discussion}

\subsection{Characterization of the Adsorbents}

The X-Ray Diffraction analysis indicated that the mineralogical composition of clays is mainly composed of smectite, quartz and smectite calcite (Figure 1). After acid activation, the disappearance of the characteristic peak of the smectite to $9.7 \AA$ (Figure 1). They recommend that this phenomenon is due to treatment heat at high temperatures.

This generates a burst of leaves which in turn changes the structure of the clay mineral. The chemical analysis showed that the main constituents of clay are silica, alumina and iron oxides (Table 1). After acid activation, percentage of both the exchangeable ions and the octahedral cations decreased while that of silica increased due to its lower solubility in acid solution (Table 2). The acid activated clay show slowly increases in specific surface area [6].

The CEC was estimated by using the copper bisethylene-diamine complex method [7]. And the results were reported in (Table 2).

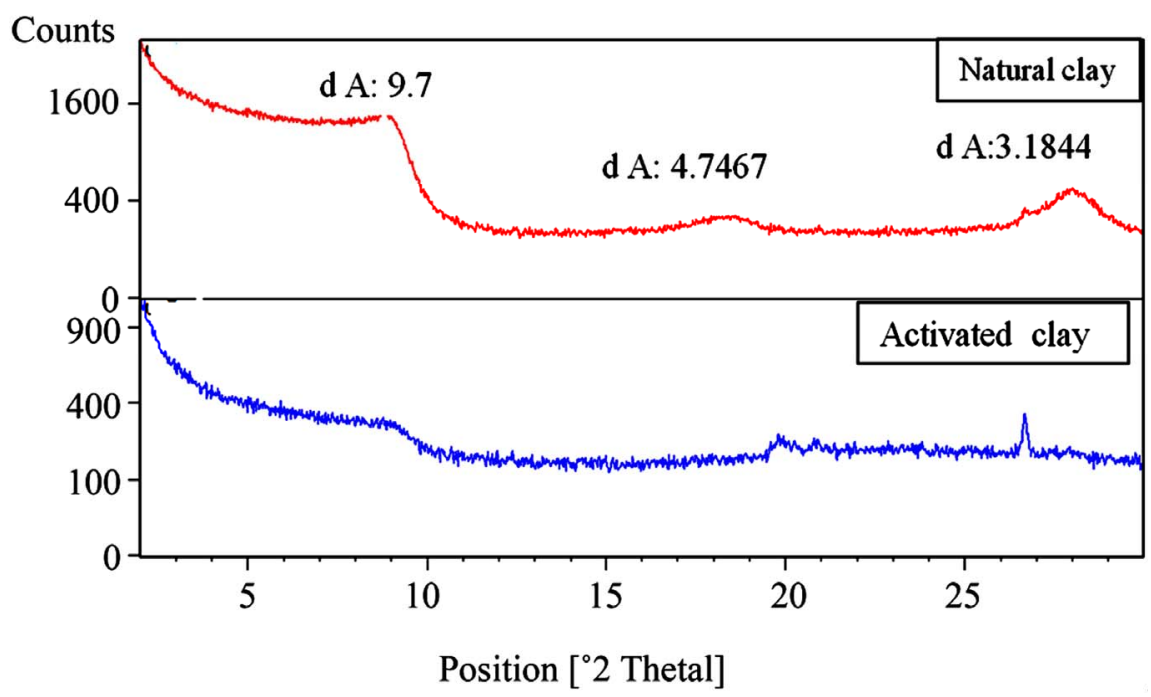

Figure 1. The X-Ray diffraction patterns of natural and activated clay. 
Table 1. Chemical characteristics of the natural and sulphuric acid-activated clay (in mass \%).

\begin{tabular}{|c|c|c|c|c|c|c|}
\hline Samples & $\mathrm{CaO} \quad \mathrm{SiO}_{2} \quad \mathrm{Al}_{2} \mathrm{O}_{3} \mathrm{Fe}_{2} \mathrm{O}_{3} \mathrm{SO}_{3}$ & $\mathrm{~K}_{2} \mathrm{O}$ & $\mathrm{Na}_{2} \mathrm{O}$ & $\mathrm{MgO}$ & $\mathrm{P}_{2} \mathrm{O}_{5}$ & LI \\
\hline $\begin{array}{l}\text { Natural } \\
\text { clay }\end{array}$ & 3.6747 .7018 .7112 .370 .96 & 1.05 & 0.96 & 2.59 & 0.32 & 16 \\
\hline $\begin{array}{l}\text { Activated } \\
\text { clay }\end{array}$ & 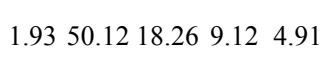 & 0.87 & 0.17 & 1.89 & 0.02 & 1 \\
\hline
\end{tabular}

LI: Lon of ignition.

Table 2. Textural, surface propreties and CEC of natural and activated clay.

\begin{tabular}{|l|c|c|c|c|}
\hline Samples & $\mathrm{S}_{\mathrm{BET}}\left(\mathrm{m}^{2} / \mathrm{g}\right)$ & $\begin{array}{c}\mathrm{V}_{\text {pores }} \\
\left(\mathrm{cm}^{3} / \mathrm{g}\right)\end{array}$ & $\begin{array}{c}\text { Diamètre moyen } \\
\text { des pores }(\AA)\end{array}$ & $\begin{array}{c}\mathrm{CEC} \\
\text { (mequiv/100 } \mathrm{g})\end{array}$ \\
\hline Natural clay & 86 & 0.1394 & 40.53 & 19.6 \\
\hline Natural clay & 140 & 0.1986 & 49.03 & 8.7 \\
\hline
\end{tabular}

\subsection{Effect of Parameters on the Adsorption of $\mathrm{Cd}^{2+}$ onto Clay}

Various parameters for the effective removal of $\mathrm{Cd}^{2+}$ ions from aqueous solutions using the natural and the acid activated clay materials as adsorbent were studied.

\subsubsection{Effect of $\mathbf{p H}$}

The $\mathrm{pH}$ of the aqueous solution is an important variable which controls the adsorption of the metal at the clay-water interfaces [8]. Hence, the influence of $\mathrm{pH}$ on the adsorption of $\mathrm{Cd}(\mathrm{II})$ onto clays was investigated in the $\mathrm{pH}$ range of 2.0 - 9. Figure 2 shows the effect of $\mathrm{pH}$ on adsorption of $\mathrm{Cd}(\mathrm{II})$ ions onto clays.

It can be observed from the results that the amount of $\mathrm{Cd}(\mathrm{II})$ ions adsorbed per unit mass (qe) of clay increases with an increase in $\mathrm{pH}$ of the solution.

At lower $\mathrm{pH}, \mathrm{Cd}(\mathrm{II})$ ions are predominant in the solution and have to complete with the large number of $\mathrm{H}^{+}$ ions for the surfaces sites, and as a result, the adsorption was comparatively low. However, at the increased $\mathrm{pH}$, $\mathrm{Cd}^{2+}$ gets free binding sites on clays and consequently uptake of $\mathrm{Cd}^{2+}$ becomes high. It has been reported in [9] that $\mathrm{Cd}(\mathrm{II})$ uptake increases above $\mathrm{pH} 6.0$ when the ions are likely to be bound strongly to hydroxyl groups $\mathrm{Cd}$ $(\mathrm{OH})^{+}, \mathrm{Cd}(\mathrm{OH})_{2}$.

However, in the present work, such a high rate of adsorption of $\mathrm{Cd}(\mathrm{II})$ fixed at $\mathrm{pH}$ 5.5.

\subsubsection{Influence of Amount of Adsorbent and Concentration of Adsorbate}

Adsorption of Cd(II) per unit mass of clay decreases as the amount of clay adsorbent increases (Figure 3).

Such results are due to the following:

1) A large adsorbent amount reduces the unsaturation of the adsorption sites, and correspondingly, the number of such sites per unit mass comes down, resulting in comparatively less adsorption at higher adsorbent amount.

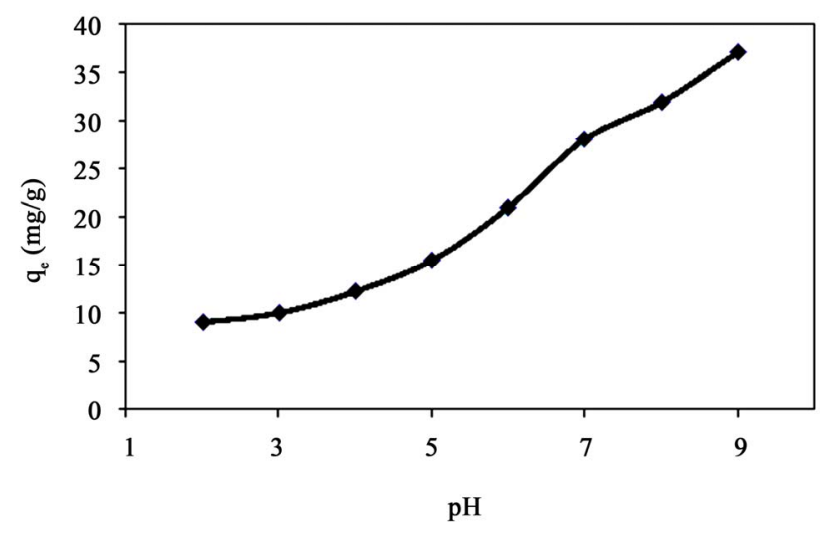

Figure 2. Amount of $\mathrm{Cd}(\mathrm{II})$ adsorbed per unit mass $\left(\mathrm{q}_{\mathrm{e}}\right)$ at $30^{\circ} \mathrm{C}$ at different $\mathrm{pH}$ (amount of clay $1 \mathrm{~g} / \mathrm{l}$, initial concentration $50 \mathrm{mg} / \mathrm{l}$, time $2 \mathrm{~h}$ ) for natural clay.

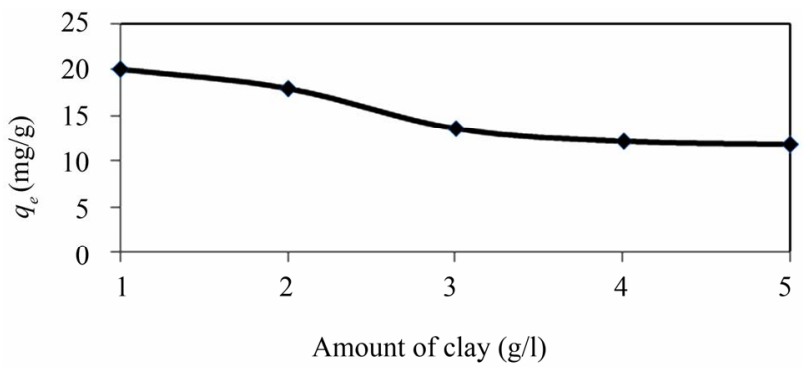

Figure 3. Amount of $\mathrm{Cd}(\mathrm{II})$ ions adsorbed per unit mass $\left(\mathrm{q}_{\mathrm{e}}\right)$ at $30^{\circ} \mathrm{C}$ at different natural clay amount (pH 5.5, initial concentration $50 \mathrm{mg} / \mathrm{l}$, time $2 \mathrm{~h}$ ).

2) When the adsorbent amount is small, the metal ions can easily access the adsorption sites and $\mathrm{q}_{\mathrm{e}}$ is high. With the rise in adsorbent load, the corresponding increase in adsorption per unit mass is less because of lower adsorptive capacity utilization of the adsorbent. This may be due to overcrowding of particles which may be termed as a kind of solid concentration effect.

Higher adsorbent amount creates particle aggregation, resulting in a decrease in the total surface area and an increase in diffusional path length, both of which contribute to a decrease in the amount adsorbed per unit mass [4].

\subsubsection{Effect of Temperature}

To examine the temperature effect on the $\mathrm{Cd}^{2+}$ ions retention, the same conditions were kept while changing the temperature. According to Figure 4, when the temperature increases, the cadmium adsorption capacities increase confirming that adsorption is an endothermic phenomenon $[4,9]$.

\subsection{Adsorption Isotherms Models}

The Cd(II) adsorption experiments isotherms were carried out at $\mathrm{pH} 6.0$ by varying the initial $\mathrm{Cd}(\mathrm{II})$ concentrations 


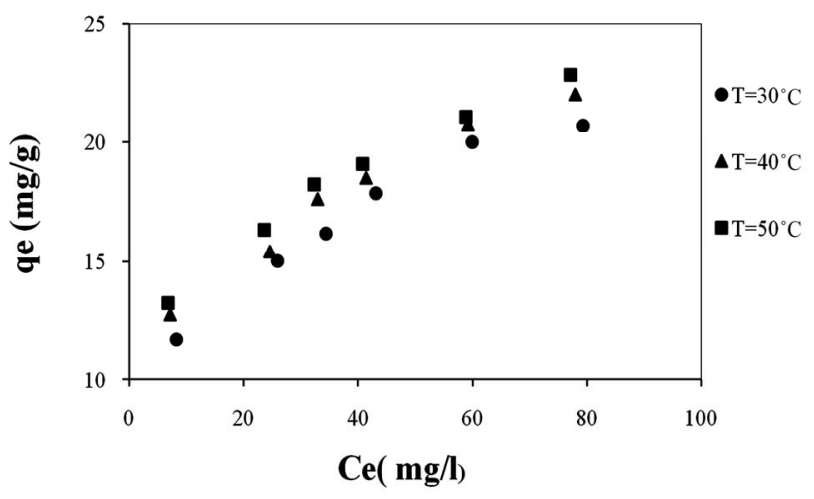

Figure 4. Effect of temperature on Cd(II) adsorption on natural clay at pH 5.5 (amount of adsorbent: $1 \mathrm{~g} / \mathrm{l}$ ).

in synthetic chemical solutions. All other parameters were kept constant. The obtained equilibrium adsorption data were fitted on the linearly transformed Langmuir and Freundlich equations [10].

The Langmuir treatment is based on the assumption that a maximum adsorption corresponds to a saturated monolayer of solute molecules on the adsorbent surface, the energy of adsorption is constant, and that there is no transmigration of adsorbate in the plane of the surface, which is represented by:

$$
\frac{C_{e}}{q_{e}}=\frac{C_{e}}{q_{m}}+\frac{1}{k_{L} \cdot q_{m}}
$$

where $q_{e}$ is the amount of heavy metal ions adsorbed per unit mass of sorbent $(\mathrm{mg} / \mathrm{g})$ at equilibrium liquid phase concentration $\left(C_{e}\right)$ of heavy metal ion $(\mathrm{mg} / \mathrm{l}), q_{m}(\mathrm{mg} / \mathrm{g})$ and $k_{L}(1 / \mathrm{mg})$ are Langmuir constants indicating sorption capacity and energy of adsorption, respectively.

The values of $q_{m}$ and $k_{L}$ were determined from the intercept and the slope of the line obtained by plotting $C_{e} / q_{e}$ versus $C_{e}$ (Figures 4 and 5).

The Langmuir monolayer adsorption capacity $\left(q_{m}\right)$ gives the amount of the $\mathrm{Cd}^{2+}$ required to occupy all the available sites per unit mass of the sample. The Langmuir monolayer adsorption capacity of $\mathrm{Cd}^{2+}$ was estimated as $21.93 \mathrm{mg} \cdot \mathrm{g}^{-1}$ and $26.74 \mathrm{mg} \cdot \mathrm{g}^{-1}$ for natural clay and activated clay, respectively (Table 3 ). These values showed a slight increase of adsorption capacity of acid activated clay compared to that of untreated clay. This increase is due to the increase in specific surface areas of clay.

The value of $k_{L}$ which related to the bonding energy coefficient [11] is greater for natural clay than activated clay. This result indicates that the adsorption of cadmium by activated clay request less energy than that of natural clay. Moreover, the high value of $k_{L}$ has been related to specifically adsorbed metal at high energy surfaces with low dissociation constants; while the low value of $k_{L}$ appears to be related to adsorption at low energy surfaces

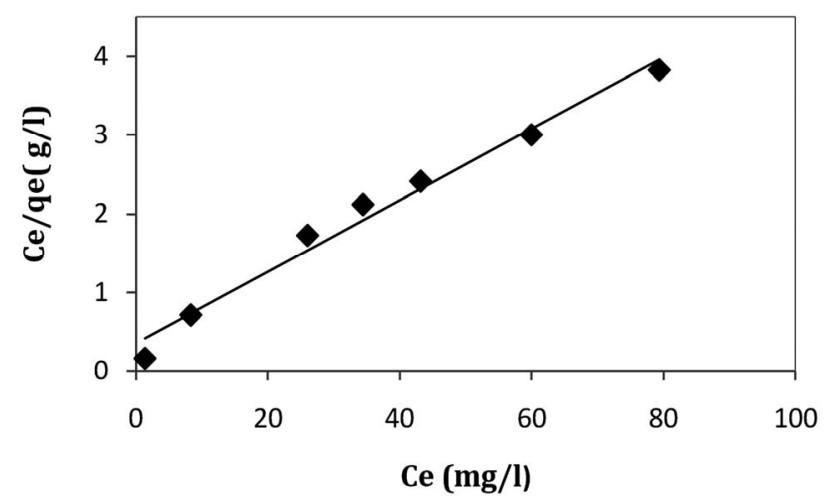

Figure 5. Langmuir isotherm for the adsorption of Cd(II) ions onto natural clay (amount of adsorbent: $1 \mathrm{~g} / \mathrm{l}, 30^{\circ} \mathrm{C}, \mathrm{pH}$ 5.5).

Table 3. Langmuir constants for Cd(II) adsorption on different samples at $30^{\circ} \mathrm{C}$.

\begin{tabular}{rcccc} 
Constants & $q_{m}(\mathrm{mg} / \mathrm{g})$ & $K_{L}(\mathrm{l} / \mathrm{mg})$ & $R^{2}$ & $R_{L}$ \\
\hline Temperature $\left({ }^{\circ} \mathrm{C}\right)$ & & & & \\
\hline Natural clay & 21.93 & 0.130 & 0.9815 & 0.0714 \\
Activated clay & 26.74 & 0.106 & 0.9992 & 0.0862 \\
\hline
\end{tabular}

with high dissociation constants $[12,13]$. So, the low of $k_{L}$ value of acid activated clay may indicate that the retention of $\mathrm{Cd}^{2+}$ on this adsorbent occurred mainly on specific adsorption positions, which are the functional surface groups ( $\mathrm{Si}-\mathrm{OH})$. On the other hand, cations exchange should be the main adsorption mechanism for acid clay. Similar results are obtained by Wang et al. [14]. The statistical significance of the correlation coefficient $\left(\mathrm{R}^{2}\right)$ was the criteria by which the fitting of the data to Langmuir isotherm was tested.

The freundlich adsorption isotherms were applied also to removal $\mathrm{Cd}^{2+}$ ions into clay,

$$
\ln \left(q_{e}\right)=\ln \left(k_{f}\right)+(1 / n) \operatorname{lnn}\left(C_{e}\right)
$$

The constants $k_{f}$ and $n$ were calculated (Table 4). $k_{f}$ is a parameter related to the temperature and $n$ is a characteristic constant for the adsorption system under the study. The values of $\mathrm{n}$ are bigger than 1 , which indicates that adsorption intensity is favorable over the entire range of concentrations studied.

In order to predict whether the adsorption process by clay is favorable or unfavorable for the Langmuir type adsorption process, the isotherm shape can be classified by a term " $R_{L}$ ", a dimensionless constant separation factor, which is defined below [11]:

$$
R_{L}=\frac{1}{1+k_{L} C_{0}}
$$


Table 4. Freudlich constants for $\mathrm{Cd}(\mathrm{II})$ adsorption on different samples at $30^{\circ} \mathrm{C}$.

\begin{tabular}{cccc}
\hline Constants & $K_{f}$ & $\mathrm{n}$ & $R^{2}$ \\
Temperature $\left({ }^{\circ} \mathrm{C}\right)$ & 7.72 & 4.554 & 0.9807 \\
Natural clay & 6.312 & 3.095 & 0.9709 \\
Activated clay & & & \\
\hline
\end{tabular}

According to the value of $\mathrm{R}_{\mathrm{L}}$ we can then know the nature of the balance which becomes established between both solid-liquid phases.

$$
\begin{aligned}
& R_{L}>1 \text { : unfavorable; } \\
& R_{L}=1 \text { : linear; } \\
& 0<R_{L}<1 \text { : favorable. }
\end{aligned}
$$

\subsection{Thermodynamic Parameters of Adsorption}

Using the following equations, in order to explain the effect of temperature on the adsorption thermodynamic parameters, standard free energy $\Delta \mathrm{G}^{0}$, standard enthalpy $\Delta \mathrm{H}^{0}$ and standard entropy $\Delta \mathrm{S}^{0}$ were determined. To calculate the values of the parameters the following equations were used:

$$
\begin{aligned}
\Delta G^{0} & =\Delta H^{0}-T \Delta S^{0} \\
\ln K_{L} & =\frac{\Delta S^{0}}{R}-\frac{\Delta H^{0}}{R T} \\
\Delta G^{0} & =\Delta H^{0}-T \Delta S^{0}
\end{aligned}
$$

where $k_{L}$ is the Langmuir constant that is related with the energy of adsorption, $\mathrm{R}$ is the ideal gas constant and $\mathrm{T}$ is the absolute temperature $(\mathrm{K})$. The calculated values of thermodynamic parameters were determined from the slops and intercepts of the plots of $\ln k_{L}$ vs. 1/T (Figure 6).

The calculated thermodynamic parameters based on the above functions are listed in Table 5.

Positive values of $\Delta \mathrm{H}^{0}$ suggest the endothermic nature of the adsorption and the negative values of $\Delta \mathrm{G}^{0}$ indicate the spontaneous nature of the adsorption process.

However, the value of $\Delta \mathrm{G}^{0}$ decreased with an increase in temperature, indicating that the spontaneous nature of adsorption is inversely proportional to the temperature.

\subsection{Comparaison of Capacity Adsorption with Other Adsorbents}

For a better valorization of our clay, the adsorbent capacity is compared (in the same operating condition) with different types of adsorbents in the literature for $\mathrm{Cd}(\mathrm{II})$ adsorption on clays (Table 6). The results show that the retention of $\mathrm{Cd}$ (II) ions onto acid-activated clays was better than their natural forms for all type of clays.
Furthermore, the adsorbents used during our work have higher maximum adsorption capacities than other adsorbents reported (Table 6), which indicated the effectiveness of the adsorbents used in the present work.

\section{Conclusions}

Several experiences were tested on samples of natural and activated smectite in this study to improve a maximum of $\mathrm{Cd}(\mathrm{II})$ adsorption capacity. Results indicate that activated forms sample adsorb better than their natural sample at $30^{\circ} \mathrm{C}$ and at $\mathrm{pH} 5.5$ during $2 \mathrm{~h}$ in adsorption batch. The experimental data fit well with Langmuir model. The effect of temperature on the adsorption of $\mathrm{Cd}(\mathrm{II})$ onto the caly samples indicated that the adsorption in an endothermic process.

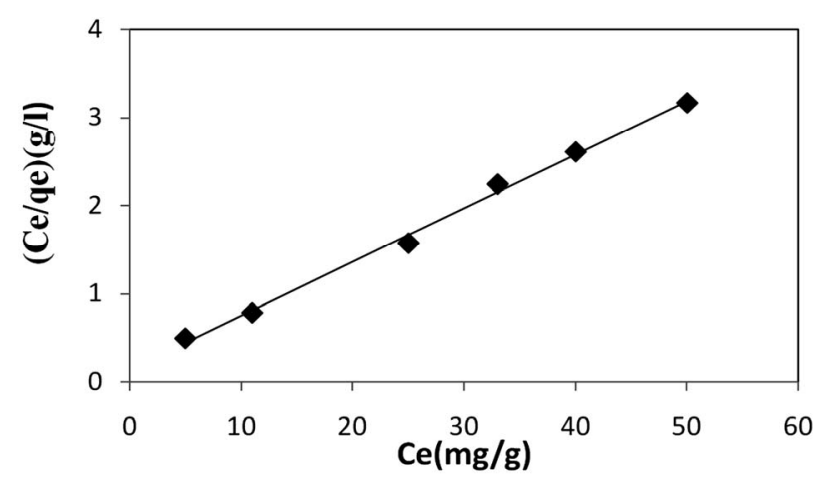

Figure 6. Langmuir isotherm for the adsorption of Cd(II) ions onto activated clay (amount of adsorbent: $1 \mathrm{~g} / \mathrm{l}, 30^{\circ} \mathrm{C}$, pH 5.5).

Table 5. Thermodynamic parameters.

\begin{tabular}{cccc}
\hline Temperature $\left({ }^{\circ} \mathrm{C}\right)$ & $\Delta \mathrm{G}^{0}(\mathrm{~kJ} / \mathrm{mol})$ & $\Delta \mathrm{H}^{0}(\mathrm{~kJ} / \mathrm{mol})$ & $\Delta \mathrm{S}^{0}(\mathrm{~J} / \mathrm{mol} \cdot \mathrm{K})$ \\
\hline 30 & -24.16 & & \\
40 & -25.2 & 7.16 & 103.34 \\
50 & -26.23 & & \\
\hline
\end{tabular}

Table 6. Comparison of the maximum adsorption capacity of $\mathrm{Cd}^{2+}$ onto different adsorbents .

\begin{tabular}{lcc}
\hline \multicolumn{1}{c}{ Adsorbent } & $\begin{array}{c}\text { Capacity ofadsorption } \\
\left(\mathrm{mg} \cdot \mathrm{g}^{-1}\right)\end{array}$ & References \\
\hline Kaolinite & 9.90 & \\
ZrO-kaolinite & 9.70 & \\
TBA-kaolinite & 9.80 & {$[15]$} \\
Montmorillonite & 32.70 & \\
ZrO-Montmorillonite & 27.70 & \\
TBA-montmorillonite & 30.00 & \\
Acid-activated Kaolinite & 11.40 & This work \\
Acid-activated montmorillonite & 33.20 & \\
Natural clay & 21.93 & \\
Activated clay & 26.74 & \\
\hline
\end{tabular}




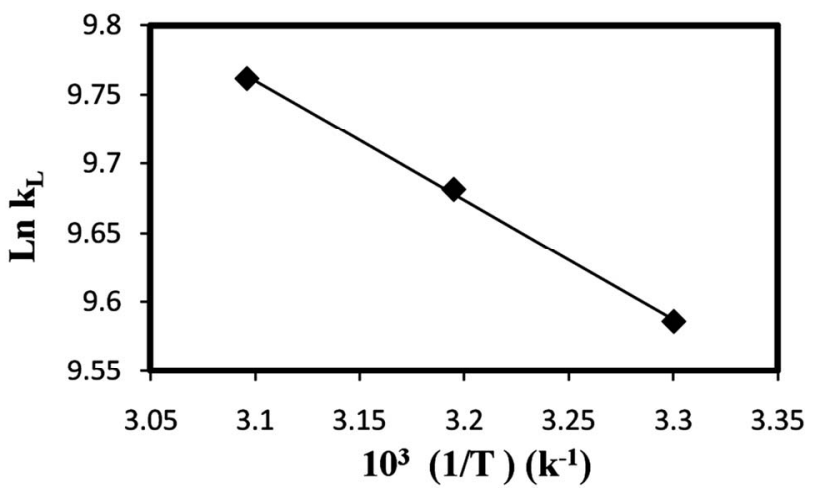

Figure 7. The van't Hoff plots for the adsorption of Cd(II) onto natural clay (amount of adsorbent: $1 \mathrm{~g} / \mathrm{l}, 30^{\circ} \mathrm{C}, \mathrm{pH} 5.5$ ).

This study provides information about the importance of natural clay materials characterization before any industrial application. Moreover, the adsorption test indicates that smectite clay has the potential to be used as an alternative adsorbent material for the cadmium ions removal from aqueous solutions.

\section{References}

[1] H. K. An, B. Y. Park and D. S. Kim, "Crab Shell for the Removal of Heavy Metals from Aqueous Solution," Water Research, Vol. 35, No. 15, 2001, pp. 3551-3556. doi:10.1016/S0043-1354(01)00099-9

[2] S. Badel and T. A. Kurniawan, "Low-Cost Adsorbents for Heavy Metals Uptakefrom Contaminated Water: A Review," Journal of Hazardous Materials, Vol. 97, No. 1-3, 2003, pp. 219-243. doi:10.1016/S0304-3894(02)00263-7

[3] K. Kadirvalu and C. Namasivayam, "Activated Carbon from Coconut Coirpith as Metal Adsorbent: Adsorption of Cd(II) from Aqueous Solution," Advances in Environmental Research, Vol. 7, No. 4, 2003, p. 471. doi:10.1016/S1093-0191(02)00018-7

[4] S. Sen Gupta and G. K. Bhattacharyya, "Influence of Acid Activation of Kaolinite and Montmorillonite on Adsorptive Removal of Cd(II) from Water," Industrial \& Engineering Chemistry Research, Vol. 46, No. 11, 2007, pp. 3734-3742. doi: $10.1021 / \mathrm{ie} 061475 \mathrm{n}$

[5] A. Gannouni, A. Bellagi and M. Bagane, "Préparation D'une Argile Activée Pour la Décolaration de L'huile D'olive c," Annual Reports in Medicinal Chemistry, Vol. 24, 1999, pp. 407-409.
[6] P. Pushpaletha, S. Rugmini and M. Latithambika, "Correlation between Surface Propreties and Catalytic Activity of Clay Catalysts," Applied Clay Science, Vol. 30, 2005, pp. 141-153. doi:10.1016/j.clay.2005.03.011

[7] F. Bergraya and M. Vayer, "CEC of Clays: Measurement by Adsorption of a Copper Ethylenediamine Complex," Applied Clay Science, Vol. 12, 1997, pp. 275-280. doi:10.1016/S0169-1317(97)00012-4

[8] H. Farrah and W. F. Pickeringf, "The Effect of pH on the Retention of $\mathrm{Cu}, \mathrm{Pb}, \mathrm{Zn}$ and $\mathrm{Cd}$ by Clay-Humic Acid Mixtures," Water Air Soil Pollution, Vol. 8, 1977, pp. 189-197. doi:10.1007/BF00294042

[9] M. J. Angove, B. B. Johnson and J. D. Wells, "The Influence of Temperature on the Adsorption of Cadmium (II) and Cobalt (II) on Kaolinite," Journal of Colloid Interface Science, Vol. 204, No. 1, 1998, pp. 93. doi:10.1006/jcis.1998.5549

[10] V. M. Boddu, K. Abburi, J. L. Talbott and E. D. Smith, "Removal of Hexavalent Chromium from Wastewater Using a New Composite Chitosan Biosobent," Environmental Science \& Technology, Vol. 37, No. 19, 2003, pp. 4449-4456. doi:10.1021/es021013a

[11] S. Kubilay, R. Gurkan, A. Savran and T. Sahan, "Removal of $\mathrm{Cu}(\mathrm{II}), \mathrm{Zn}(\mathrm{II})$ and $\mathrm{Co}(\mathrm{II})$ Ions from Aqueous Solutions by Adsorption onto Natural Bentonite," Adsorption, Vol. 13, No. 1, 2007, pp. 41-51. doi:10.1007/s10450-007-9003-y

[12] W. H. Van Riemdijik, G. H. Bolt, L. K. Koopal and J. Blaakmeer, "Electrolyte Adsorption on Heterogeneous Surfaces: Adsorption Models," Journal of Colloid and Interface Science, Vol. 109, No. 1, 1985, pp. 219-228. doi:10.1016/0021-9797(86)90296-1

[13] R. Adhikari and M. V. Singh, "Sorption Characteristics of Lead and Cadmium in Some Soils of India," $\mathrm{Ge}$ oderma, Vol. 114, No. 1, 2003, pp. 81-92. doi:10.1016/S0016-7061(02)00352-X

[14] W. Wang, H. Chen and A. Wang, "Adsorption Characteristics of Cd(II) from Aqueous Solution onto Activated Palygorskite," Separation and Purification Technology, Vol. 55, 2007, pp. 157-164. doi:10.1016/j.seppur.2006.11.015

[15] S. Sen Gupta and G. K. Bhattacharyya, "Removal of Cd (II) from Aqueous Solution by Kaolinite, Montmorillonite and Their Poly (oxo zirconium) and Tetratylammonium Derivates," Journal of Hazardous Materials, Vol. 128, No. 2-3, 2006, pp. 247-257. doi:10.1016/j.jhazmat.2005.08.008 


\section{List of Symbols}

$q_{e}$ : The amount of Cd(II) ions adsorbed $\left(\mathrm{mg} \cdot \mathrm{g}^{-1}\right)$.

$C_{0}$ : The initial aqueous concentration of Cd(II) $\left(\mathrm{mg}^{-1} \mathrm{l}^{-1}\right)$.

$C_{e}$ : The equilibrium aqueous concentration of $\mathrm{Cd}(\mathrm{II})$ $\left(\mathrm{mg} \cdot \mathrm{l}^{-1}\right)$.

$V$ : The volume of the solution (1).

$m$ : The weight of the adsorbent $(\mathrm{g})$.

CEC: The cation exchange capacity (mequiv/100 g). $q_{m}$ : Langmuir constants indicating sorption capacity (mg/g).

$k_{L}$ Langmuir constants energy of adsorption (1/mg).

$\Delta \mathrm{G}^{0}$ : Standard free energy.

$\Delta \mathrm{H}^{0}$ : Standard enthalpy.

$\Delta \mathrm{S}^{0}$ : Standard entropy. 